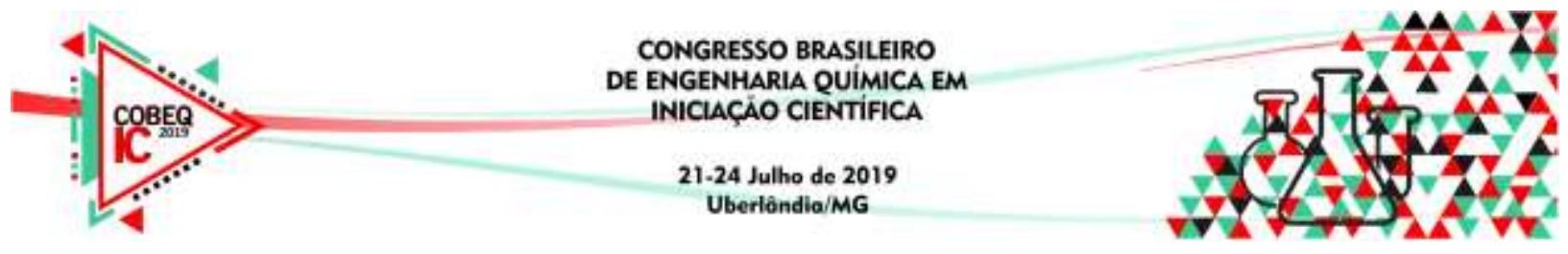

\title{
Catalisadores de Platina Suportados em Diferentes Zeólitas para Aplicação na Obtenção de Propeno a partir de Acetona
}

\author{
V.I.O. SUMIKAWA ${ }^{1}$, B.M. JURNO ${ }^{1}$ e A.P. FERREIRA ${ }^{1}$ \\ ${ }^{1}$ Universidade Federal de São Carlos, Departamento de Engenharia Química \\ E-mail para contato: apf@ufscar.br
}

\begin{abstract}
RESUMO - De modo a obter uma rota sustentável para a produção de propeno, monômero do plástico polipropileno e produzido a partir de petróleo, catalisadores bifuncionais compostos por um metal que atua no processo de hidrogenação e uma zeólita que atua no processo de desidratação podem ser aplicados no processo de transformação de acetona em propeno, uma alternativa para a atual produção de propeno via craqueamento do petróleo ou gaseificação do carvão. Neste projeto, o objetivo foi a preparação e caracterização de catalisadores bifuncionais possíveis para obtenção de propeno a partir da acetona, para isso foram utilizados catalisadores monometálicos de Platina $(\mathrm{Pt})$ suportados em diferentes zeólitas: HZSM-5, Y e Beta. Após a preparação dos catalisadores bifuncionais, foi realizada as caracterizações das zeólitas comerciais, calcinadas e impregnadas através das análises de Difração de Raios X (DRX), Redução a Temperatura Programada (TPR) e Adsorção de N2 (BET).
\end{abstract}

\section{INTRODUÇÃO}

O propeno é um composto químico que possui alto valor agregado e é muito utilizado na indústria. A maior parte do propeno produzido provém do petróleo, porém a busca por fontes renováveis deste produto vem aumentando tanto no meio acadêmico quanto no industrial. Dentre as fontes alternativas podem ser citados o etanol, em um leito catalítico de zeólita HZSM-5, ou o isopropanol, através de uma reação de desidratação em presença de catalisador ácido. Tanto o etanol quanto o isopropanol podem ser obtidos por processos de fermentação de biomassa, mas o isopropanol em particular pode ser sintetizado pela hidrogenação de acetona sobre catalisadores metálicos ou então pela hidratação do propeno.

A acetona, composto oxigenado de três carbonos, pode ser obtida a partir de fontes renováveis, como subproduto da fermentação para produção de butanol ou ainda na fase aquosa do bio-óleo obtido por pirólise de biomassa. A patente US 2011/0230696 A1 (OHKUBO et al., 2011) descreve o processo para a produção do propeno a partir de acetona, utilizando dois catalisadores distintos em única etapa: consiste na hidrogenação da acetona com um catalisador contendo cobre (catalisador comercial composto por óxidos de cobre, zinco e alumínio), seguida da desidratação do isopropanol formado sobre um sólido com propriedades ácidas (zeólita Beta), produzindo, assim, a olefina de interesse.

$$
\text { Acetona }+\mathrm{H} 2 \leftrightarrow \text { isopropanol } \leftrightarrow \text { propeno }+\mathrm{H} 2 \mathrm{O} \rightarrow \text { propano }
$$




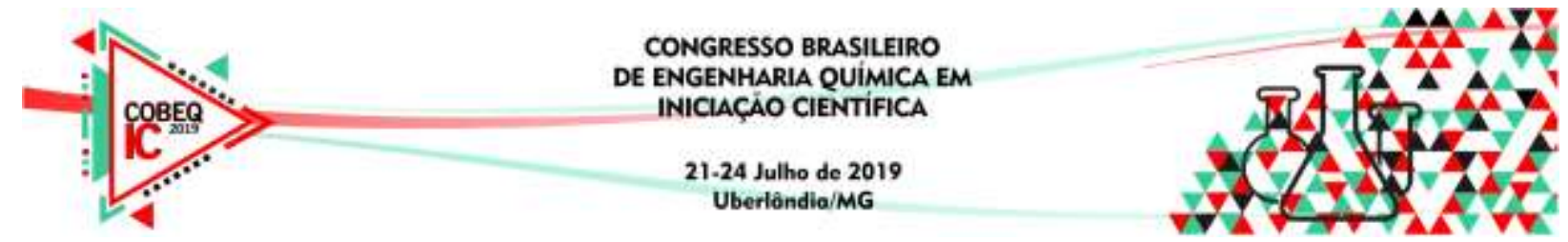

A rota química proposta é a reação de hidrogenação da acetona, em presença de um catalisador monometálico de Platina, seguida da desidratação do isopropanol com um catalisador de Zeólita. Especificamente, serão utilizados catalisadores monometálicos de Pt suportados na Y, ZSM-5 e Beta com diferentes razões Si/Al sendo realizada análises de suas características através da Difração de Raios X (DRX), Redução a Temperatura Programada (TPR) e Redução a Adsorção de N2 (BET).

\section{MATERIAIS E METODOLOGIA}

As vidrarias utilizadas foram limpadas com água régia, uma mistura de ácido nítrico e ácido clorídrico concentrados na proporção de uma parte para três, de modo a retirar as impurezas. As zeólitas comerciais utilizadas como suporte foram a Zeólita Y com cátion nominal na forma de hidrogênio (HY CBV-720) com razão Si /Al de rede igual a 30 e Si/Al global de 15, a Zeólita ZSM-5 com cátion nominal na forma de amônio(NH4 ZSM-5 CBV5524) com Si/Al=25 e a Zeólita Beta com cátion nominal na forma de amônio (NH4BEA CP 814C) com $\mathrm{Si} / \mathrm{Al}=38$. As Zeólitas foram calcinadas em reator de calcinação em duas rampas de temperatura, a primeira rampa foi de $200^{\circ} \mathrm{C}$ por 60 minutos e a segunda rampa foi de $500^{\circ} \mathrm{C}$ por 120 minutos ambas com variação de $2^{\circ} \mathrm{C}$ por minuto e vazão de ar de $80 \mathrm{~mL} / \mathrm{min}$, sendo feita para uma quantidade superior a 1 grama. Após a calcinação das zeólitas foi feito o processo de impregnação com o precursor metálico da platina, de modo a obter um teor de $1,5 \%$ em cada amostra.

Para a impregnação, foi calculado a quantidade de zeólita e sal precursor necessário de modo a obter aproximadamente 1 grama da platina impregnada em cada zeólita com o teor desejado. As zeólitas foram pesadas em béquer de $100 \mathrm{~mL}$ em uma balança analítica com fundo de escala de 4 casas decimais, as massas medidas foram 1,0022g para zeólita Y e 1,0016g para zeólita ZSM-5, a massa de sal precursor pesado em béquer de $25 \mathrm{~mL}$ foram de 0,0404g utilizada para impregnar a zeólita Y e 0,0407 utilizada para impregnar a ZSM-5. As zeólitas foram impregnadas à $80^{\circ} \mathrm{C}$ em chapa de aquecimento, para isso, o sal precursor foi dissolvido em água e pipetado sobre as zeólitas em baixa quantidade sendo misturado com bastão de vidro. Após a impregnação, as amostras foram secas em estufa a temperatura de $80^{\circ} \mathrm{C}$ no período da noite, no dia seguinte, foi realizado o processo de calcinação utilizando as mesmas duas rampas anteriores, de $200^{\circ} \mathrm{C}$ por 60 minutos e $500^{\circ} \mathrm{C}$ por 120 minutos a $2^{\circ} \mathrm{C} / \mathrm{min}$ e vazão de ar de $80 \mathrm{~mL} / \mathrm{min}$. Após esse procedimento experimental foi feito as análises das zeólitas comerciais, calcinadas e impregnadas de modo a caracterizadas, foram feitas as análises difração de raios X (DRX), redução a temperatura programada (RTP) e dessorção a temperatura programada (DTP).

\section{RESULTADOS E DISCUSSÃO}

\subsection{Difração de Raios-X:}

Comparando-se os difratogramas experimentais com os da literatura observa-se que os picos são localizados nas mesmas angulações, havendo uma leve diferença no tamanho das intensidades. Para a zeólita Y, os picos cristalinos de intensidade ocorrem em $2 \Theta=6,10,12$, $16,19,24,27,31$ e 32, como pode ser visto no difratograma referencial (Salahuueen, 2015) e experimental na Figura 1.a). Para a Zeólita ZSM-5, os picos cristalinos de intensidade 


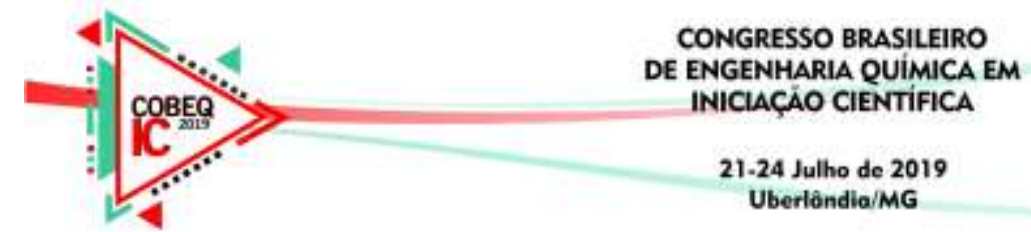

ocorrem em em $2 \Theta=7,9^{\circ} ; 8,9^{\circ}, 14,85^{\circ}, 23,13^{\circ}, 23,92^{\circ}, 24,4^{\circ}, 26,9^{\circ}$ e $29,96^{\circ}$, como pode ser visto no diagrama referencial (FRANTZ, 2015) e experimental na Figura 1. b). Para a Zeólita Beta, os picos cristalinos de intensidade ocorrem em em $2 \Theta=7,79^{\circ}, 13,46^{\circ}, 14,6^{\circ}, 21,5^{\circ}$ e $22,5^{\circ}$ e 27,25, como pode ser visto no diagrama referencial (LIMA, 2008) e experimental na Figura 1.c).

Figura 1 - Difratograma Experimental das Zeólitas: a) Zeólita Y; b) Zeólita ZSM-5 e c) Zeólita Beta, na forma Comercial, Calcinada e Impregnada com Platina.

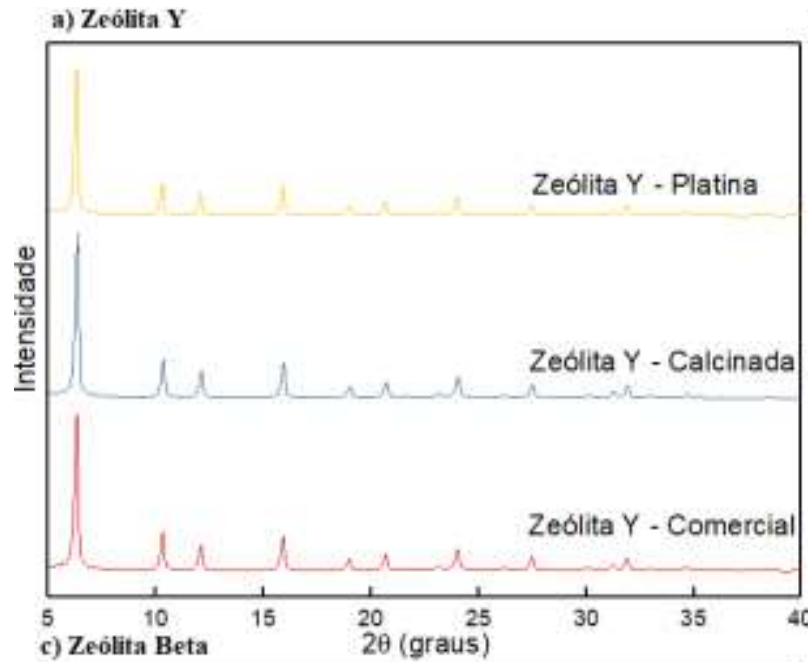

b) Zeólita ZSM-5
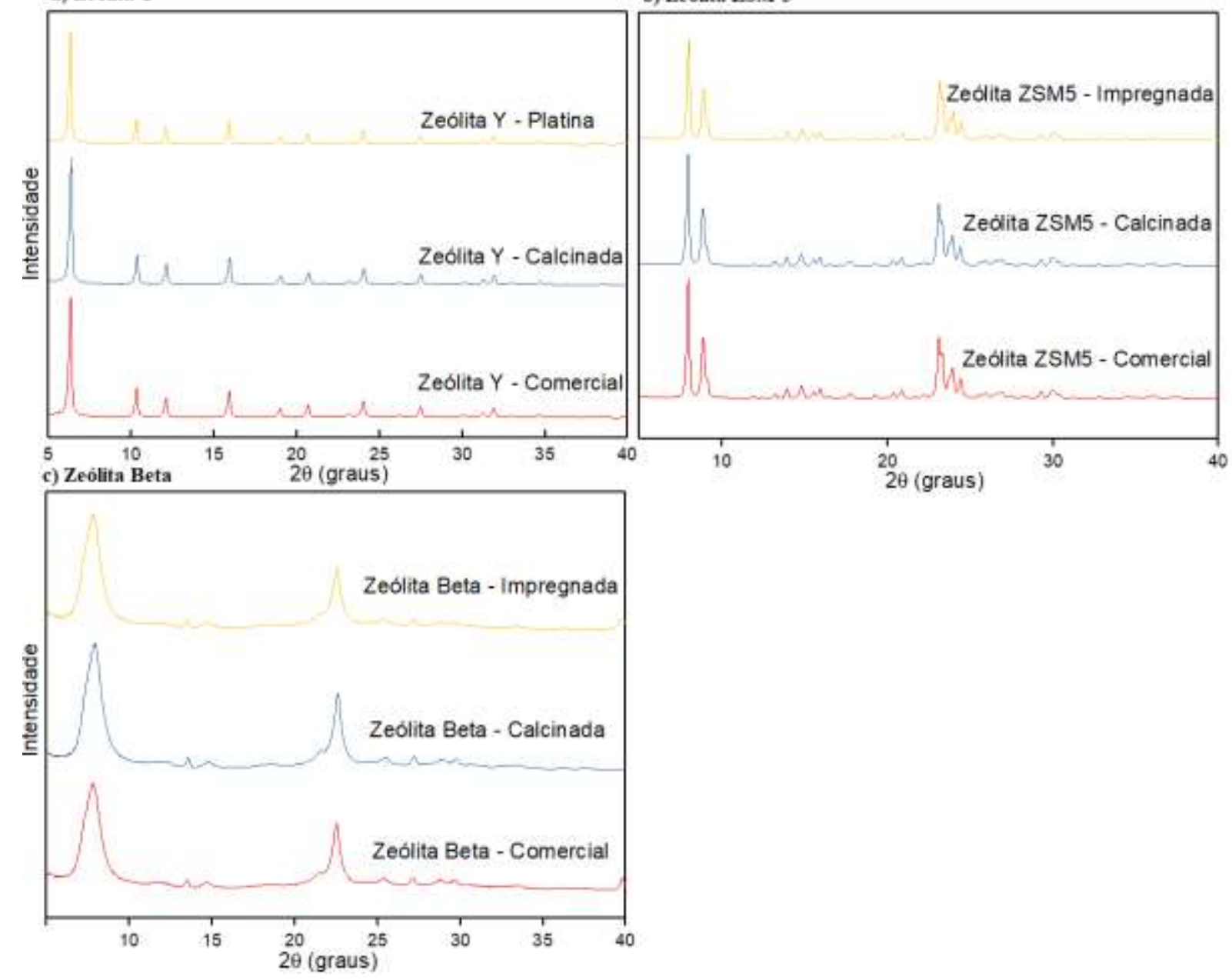

A partir das intensidades e picos de cristalinidade, foi possível possível obter as porcentagens de cristalinidade de cada amostra como pode ser visto na tabela 1 a seguir, as amostras comerciais e calcinadas apresentam intensidades de pico muito próximas, logo suas cristalinidades são praticamente iguais.

Tabela 1 - Cristalinidade das amostras de Zeólita.

\begin{tabular}{|c|c|}
\hline Amostra & Cristalinidade (\%) \\
\hline Zeólita Y - Calcinada & 81 \\
\hline Zeólita Y - Impregnada & 87 \\
\hline
\end{tabular}




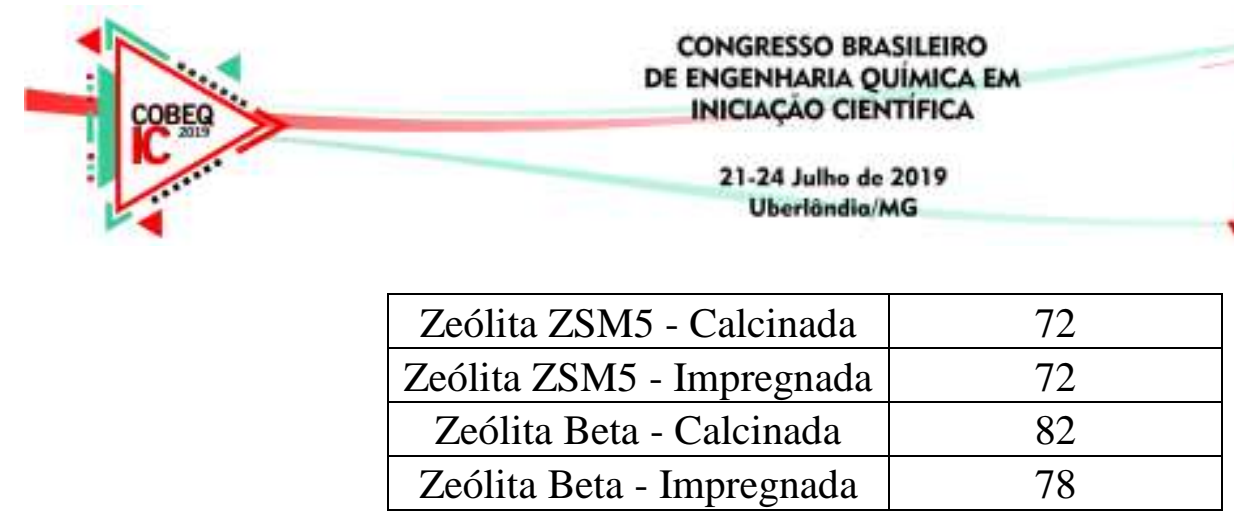

\subsection{Redução a Temperatura Programada (TPR):}

A partir das análises de redução a temperatura programada (TPR) é possível verificar as fases redutíveis do material, durante o procedimento o material foi submetido a uma atmosfera redutora utilizando-se hidrogênio com variações de temperatura, desse modo, cada pico representa um processo de redução da espécie oxidada. Para as zeólitas comerciais, Figuras 4.a) e 6.a), e calcinadas, Figuras 4.b) e 5.a), esperava-se que não houvessem picos significativos (LONGATI A.A., 2014), pois elas não interagem com o H2 na ausência de um metal impregnado, porém na prática experimental é observada uma curva suave formada indicando possivelmente a necessidade de melhor calibração do equipamento, já para as zeólitas impregnadas há notáveis picos de alta intensidade, para a zeólita Y impregnada com Platina na temperatura de $399,02^{\circ} \mathrm{C}$, observada na Figura 4.c), para zeólita ZSM-5 impregnada com platina na temperatura de $734,27^{\circ} \mathrm{C}$, observada na Figura 5.b), e na zeólita beta impregnada com platina na temperatura de $420,64^{\circ} \mathrm{C}$, observada na Figura 6.b), indicando uma fase redutível da Platina (Pt) impregnada nas zeólitas.

Figura 4 - Perfis de Redução a Temperatura Programada das Zeólita Y a) Comercial, b) Calcinada e c) Impregnada com Platina.
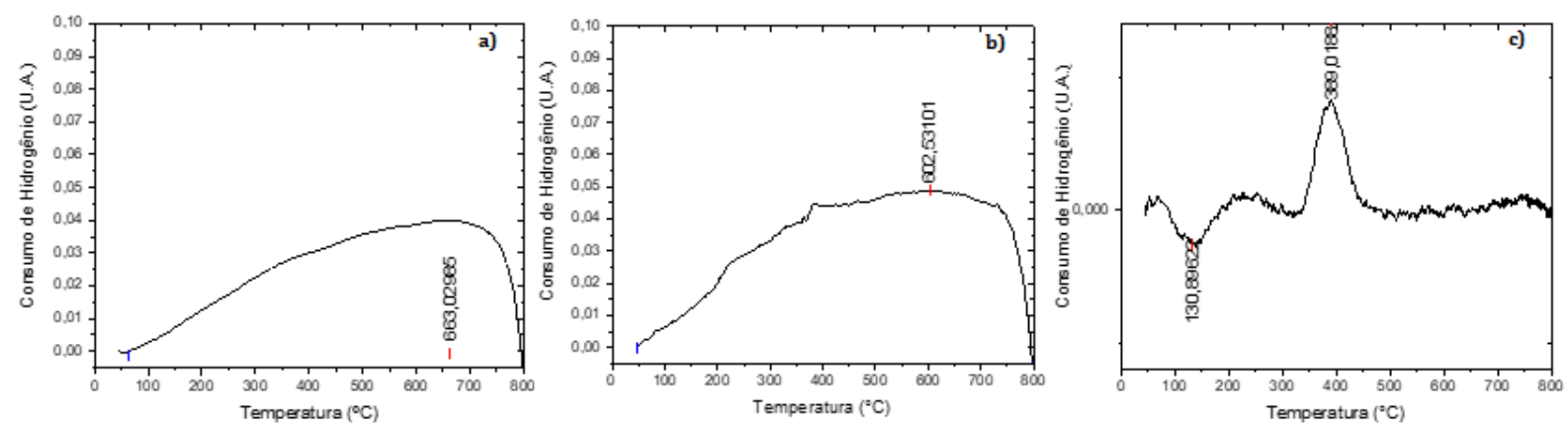

Figura 5 - Perfis de Redução a Temperatura Programada das Zeólita ZSM5 a) Calcinada e b) Impregnada com Platina.
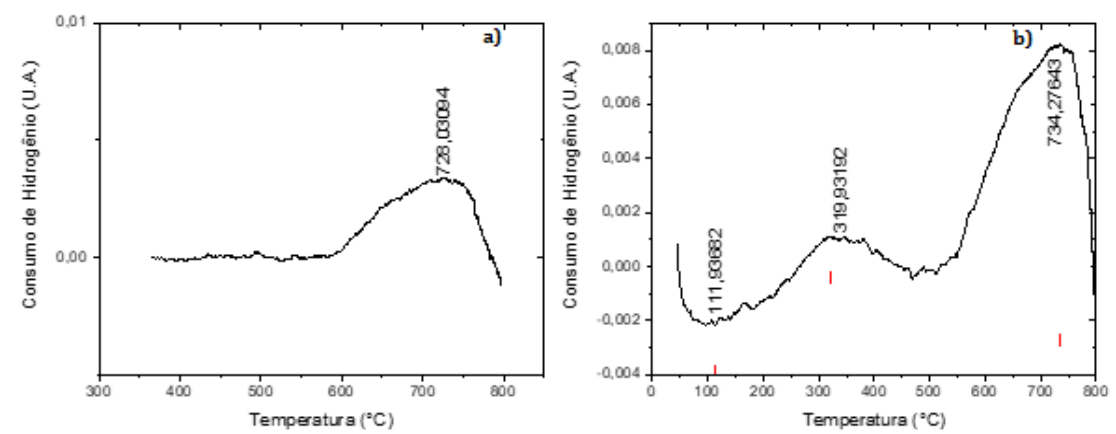

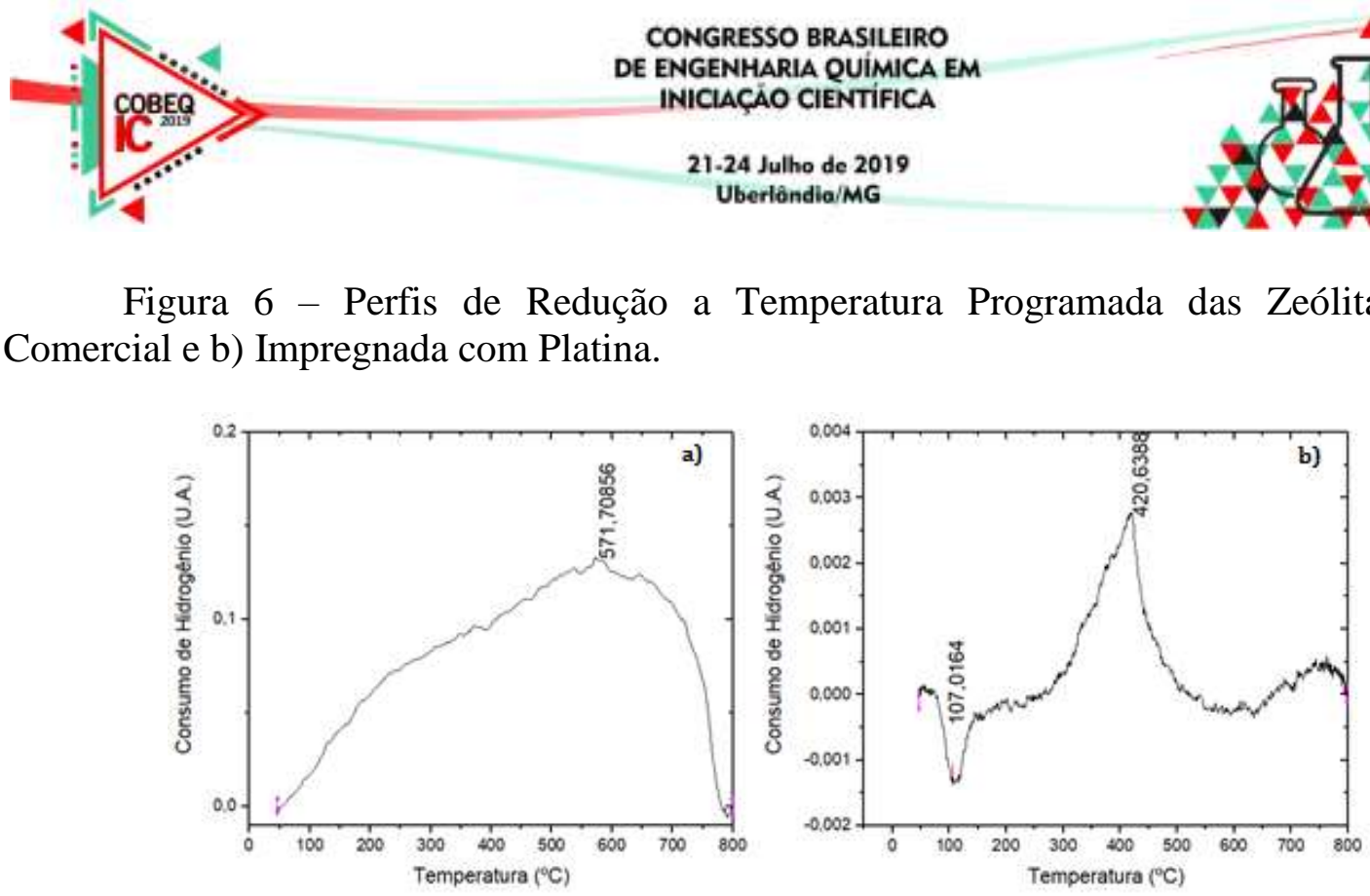

\subsection{Adsorção de $\mathrm{N}_{2}$ (BET):}

A análise de adsorção de $\left(\mathrm{N}_{2}\right)$ foi realizada com a finalidade de se obter informações sobre a área específica pelo método de cálculo BET e a estrutura porosa do sólido. As isotermas de adsorção utilizando nitrogênio são dadas pela figura 7.a), 7.b) e 7.c).

Figura 7 - Isotermas de Adsorção das Zeólitas: a) Zeólita Y; b) Zeólita ZSM-5 e c) Zeólita Beta, na forma Comercial, Calcinada e Impregnada com Platina.
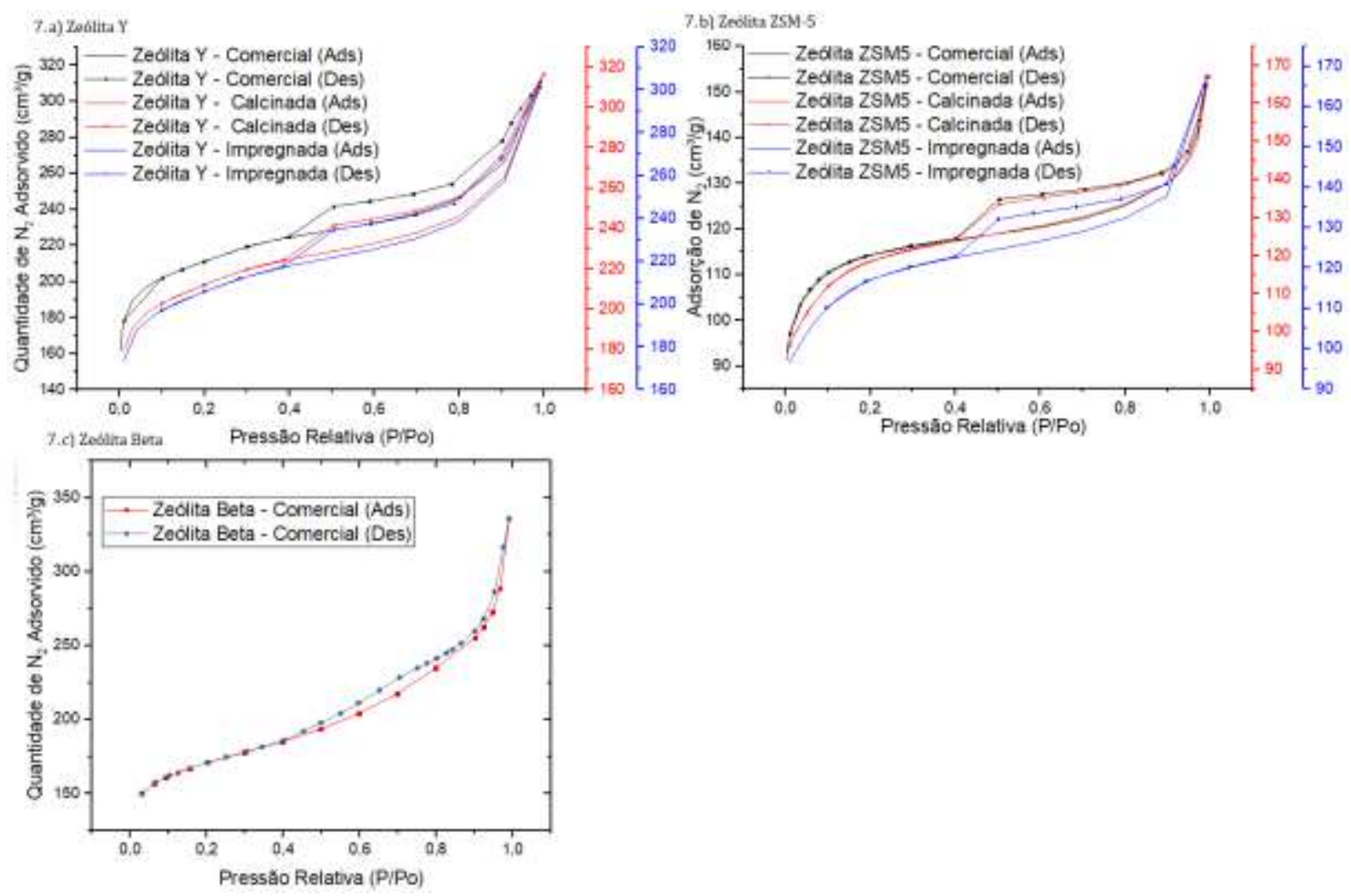


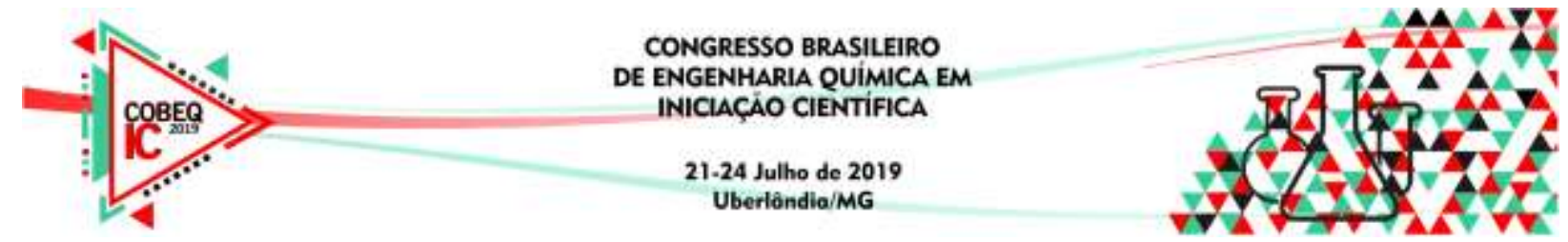

De acordo com a IUPAC as isotermas obtidas são classificadas como isotermas do Tipo IV, no qual a presença de histerese entre a curva de adsorção e a de dessorção indica a presença de mesoporos nas estruturas zeolíticas microporosas, além disso, através dos dados da Tabela 2, verifica-se que a área específica BET tem valor elevado, característico em sólidos microporosos.

Tabela 2 - Área Específica Calculada pelo método BET.

\begin{tabular}{|c|c|}
\hline Catalisador & Área Específica $\left(\mathrm{m}^{2} / \mathrm{g}\right)$ \\
\hline Zeólita Y - Comercial & 721 \\
\hline Zeólita Y - Calcinada & 725 \\
\hline Zeólita Y - Impregnada & 702 \\
\hline Zeólita ZSM5 - Comercial & 390 \\
\hline Zeólita ZSM5 - Calcinada & 406 \\
\hline Zeólita ZSM5 - Impregnada & 402 \\
\hline Zeólita Beta - Comercial & 591 \\
\hline Zeólita Beta - Impregnada & 560 \\
\hline
\end{tabular}

\section{CONCLUSÃO}

Neste trabalho foi feita a preparação e análise das zeólitas Y, ZSM-5 e Beta, nas formas comerciais, calcinadas e impregnadas com platina. Após a preparação dos catalisadores, foram feitas as análises de DRX, no qual foi possível observar os picos característicos que identificam as amostras e quantificar sua cristalinidade, já com as análises de TPR foi possível observar que as fases redutíveis dos catalisadores bifuncionais, que ocorrem devido à platina impregnada, ocorrem em diferentes temperaturas e por fim, foi visto as características estruturais através das isotermas de adsorção e com o cálculo da área específica pelo método BET.

\section{REFERÊNCIAS}

FRANTZ, T.S. Síntese e Caracterização de Zeólitas do tipo ZSM-5 para a adsorção de CO2, Rio Grande do Sul, 2015.

LIMA, P.M. Isomerização do n-hexano sobre catalisadores Pt-Ni suportados na zeólita HBEA nanocriatalina, tese de doutorado, São Carlos-SP,Brasil, p. 79, 2008.

LONGATI A.A., Chemical conversion of no and co on catalysts based on cobalt or iron oxides, Quím. Nova v.37 nº.2, São Paulo, Apr. 2014.

OHKUBO, T; FUJIWARA, K FUJITA, T. Mitsui. Olefin production process. Chamicals Inc (JP) US 2011/0230696 A1, 22 set. 2011.

SALAHUDEEN, N. Microwave-Assisted Adsorptive Desulfurization of Model Diesel Fuel Using Synthesized Microporous Rare Earth Metal-Doped Zeolite Y. The Journal of Engineering Research v.12, nº1. 2015. 